\title{
HOW KNOWLEDGE CAN IMPACT ON THE QUALIFICATION OF NURSING AND HEALTH PRACTICE?
}

The current subject was recently the object of a roundtable discussion at the $19^{\text {th }}$ National Seminar on Nursing Research (NSNR), held in João Pessoa, Paraíba. This event is traditionally promoted by the Brazilian Nursing Association (BNA), and carried out by the Brazilian Nursing Association, Section Paraíba (BNA-Section PB), last May. It is an honor for me to use the Text \& Context Nursing Journal as an instrument to disseminate some reflections on the concretization of the $19^{\text {th }}$ NSNR.

Very recently, no one was comfortable saying there was a science in our area. Here in Brazil we began to talk about nursing science, in a more affirmative way only from a historical perspective released on the trajectory of the construction of knowledge in our country; as a product, above all of our successful decision to maintain ourselves as centers of higher education and university, demanding the training of masters and doctors.

Science is a part of knowledge or one of the forms of knowledge that we can produce, more lately it became almost the most important. In the meantime, what science are we talking about? Of the one the lead to deep reflection? Of those that inform the professional practice and that give security to the people with whom we interact in the acts careers, aid and educational?

That hegemonically practiced by our researchers - the Cartesian - will hardly be able to interpret, translate and impact on the daily actions of care given to individuals, families and communities, Why? The answer to this question is that the paradigms that support this form of manifestation or construction of the nursing science is not totalizing and is not able to learn the phenomena in movement.

Care is a phenomenon in movement, besides being obviously a social phenomenon, better said, produced in society, for and by the human being. In nursing care, we measure, check, hear, literally palpate or just with the other senses. The parameters can say something, but they do not say everything. They do not say what is important, what is more definitive about the care that is being or will be performed. What is on our front is more complex than can at first sight be measured or approximated by that which is visible. The invisible is the essential, the wound we see is important to be evaluated, of course, but more important is the person who has that wound and how it relates to life, the world, its past and looking to the future. And here comes the imponderable: care is often given between people, even if mediated by "things." And on our side here - of nurses - we can say that it has the same complexity as a human being, although, unfortunately, it is "domesticated" by the canons of professional pragmatism and properly (or not) regulated by professional acetic standards. Invariably this domestication eliminates the essential, the complexity of the relationship (in nursing care) itself; Of the interface itself; Of the human being in movement, in itself.

Although all caregivers know that there is caregiver, caring and care itself, that vital, dynamic and unique production is not given much importance, as if looking at pieces or parts or parts of some way We could, by magically taking care to reconstruct the fractured totality by our "Scientific-Cartesian" gaze.

It is necessary, then, to "recompose" the whole, to elaborate the dialectical synthesis of the contradictory movement, to reveal the dialectic of the whole/part, the essence and the appearance, to recover dynamicity and to re-look at historicity.

For this, I recommend a daily exercise of thinking and talking with the peers about some questions: how much of our nursing science that deals directly or immediately with the human is really humanized? Considering its complexity of living the health process? How does the producer of the knowledge (researcher) self-verify as part of the totality of production of health services, that is, the same with potentialities and wear and tear of the way they are inserted at work? Do the nursing investigations inform (more) for 
the institute or (more) for the institute? Do they inform for a solidarity, participative or maintenance of inequality of power through knowledge? According to projects to meet the possibilities of development agencies or certain groups instituted is a strategy for the production of emancipatory knowledge (the profession and professionals, as well as users) or has been an end in itself?:270

What paradigms do we speak of when We think of nursing sciences? The one that allows us to understand the phenomena of nursing in its density? In its quality? Those methodically and ethically supported to be able to respond honestly to the scientific doubts of nursing?

There are many ways of taking these reflections into the daily practice of our professional practices and, for this reason, make our knowledge produced capable of impacting professional practices. I would like to suggest some books, beyond the classics, that can help on this reflection: a) "Advanced qualitative research in nursing" ${ }^{\prime 2}$. In this book, I would emphasize Sandelowski's reading of material culture of nursing; B) Qualitative research: innovation, dilemmas and challenges"3 emphasizing in it the chapter "About quality in qualitative research in nursing". ${ }^{4}$ I would also like to suggest careful reading of precious articles from Text \& Context Nursing Journal, especially in the last two years, because in addition to a broad thematic spectrum, the articles prevail for the ability to do-think, reflect and not only demonstrate results of well-designed research. Profitable readings can also be found in the Journal of the School of Nursing of São Paulo. In this one, which completes its $50^{\text {th }}$ anniversary, the issues for discussion and reflection are diffused, quite strong in the beginning (with the writings of Wanda de Aguiar Horta on the nursing process) and re-acquiring reflexive force in the last three to five years. Other Brazilian nursing journals can also be included as sources of debate... Share with colleagues, students, advisors, professionals inside and outside of the nursing science!

Enjoy your reading and continuity this reflection!

\section{REFERENCES}

1. Egry EY. A look at the nursing sciences: the analytical aspects of care practices. Rev Esc Enferm USP 2001; 35 (3): 265-70.

2. Latimer J. Advanced qualitative research for nursing. Lisboa (PT): Sesílito; 2005.

3. Costa AP, Coutinho CP, Souza DN, Egry EY, Souza FN, Zarco J, et al. Qualitative research: innovation, dilemmas and challenges. Vol 2. Aveiro (PT): Ludomedia / RealBase; 2015.

4. Egry EY, Fonseca RMGS. About the quality of qualitative research in Nursing. In: Costa AP, Coutinho CP, Souza DN, Egry EY, Souza FN, Zarco J, et al. Qualitative research: innovation, dilemmas and challenges. Vol 2. Aveiro (PT): Ludomedia / RealBase; 2015. p.75-102.

\section{Emiko Yoshikawa Egry}

Full Professor, retired from the School of Nursing of the University of São Paulo.

Scientific Editor of the Journal of the Nursing School of the University of São Paulo.

Coordinator of the Advisory Committee of the Nursing Area of CNPq 2015-2018 